\title{
Prevalence of metabolic syndrome in relatives of patients with type 2 diabetes
}

\begin{abstract}
Background: Type 2diabetes and overweight and obesity rates have reached epidemic proportions. Metabolic syndrome (MS) constitutes a cluster of conditions characterized by abdominal obesity, dysglycemia and hypertension. There is a scarcity of data on metabolic parameters of non-genetically related family members of subjects with type 2diabetes (DM2) in Pakistan. These members may well be sharing unhealthy lifestyles with their diabetic spouse. We aimed to estimate prevalence of MS in blood and non blood relatives of patients known to have DM2, presenting to the diabetes clinic.
\end{abstract}

Methods: We conducted a cross-sectional study at the Diabetes clinic at the Aga Khan University Hospital, Karachi, Pakistan. Enrolled were siblings of randomly selected DM2 subjects, and spouse of the same DM2 (index groups). These groups had their anthropometry, fasting blood sugars and cholesterol measured. They were compared to siblings and spouses of non-diabetic patients (referent group), after being subjected to the same physical measurements and blood testing as the index groups.

Results: Of the 230siblings enrolled, complete data was available for 197. Mean age of index sibling, $(\mathrm{n}=112)$ was $34 \pm 10.7$; referent: $(\mathrm{n}=85) 35.7 \pm 10.5(\mathrm{p}=0.24)$. Of 230 spouses enrolled, complete data was available for 187 spouses-mean age of index spouse, $(\mathrm{n}=84)$, was 49.6 \pm 11.0 ; referent: $(\mathrm{n}=103) 48.7 \pm 9.3(\mathrm{p}=0.1)$. No significant association in overall prevalence of MS in sibling and spouse of individuals with DM2, versus sibling and spouse of non-diabetics was found. There was significant association of high waist circumference in both siblings. 1.04(1.006-1.07) and spouses. 1.03(1.007-1.06) of diabetics versus referents.

Conclusion: Abdominal obesity needs to be an integral aspect of cardiovascular disease (CVD) risk assessment. Health care providers need to incorporate spousal history of CVD and DM2 when taking family history from presenting patient. Advice regarding lifestyle modification is best targeted at the couple together, even if one partner appears to be nondiseased.

Keywords: metabolic syndrome, relatives, family, spouse, sibling, obesity
Volume 6 Issue I - 2018

Azra Rizwan, Qamar Masood, Jaweed Akhter, Najmul Islam, Abdul Jabbar, Aisha Sheikh

Aga Khan University Hospital, Karachi, Pakistan

Correspondence: Rizwan, Dow University of Health Sciences, Pakistan,Email azra.rizwan@aku.edu

Received: November 21, 2017 | Published: February 14, 2018

\section{Introduction}

Type 2 diabetes and overweight or obesity are two closely related conditions often referred to as epidemics. Based on current definitions, type 2 diabetes has afflicted an estimated 24 million people in the United States, ${ }^{1}$ with an increase of more than 3 million occurring in recent years. ${ }^{2}$ Recent years have also witnessed a tremendous rise in the prevalence of these conditions in the Asian population, ${ }^{3,4}$ with a replication of the epidemic once considered exclusive to the West. ${ }^{5-8}$

The metabolic syndrome constitutes a cluster of conditions characterized by abdominal obesity, or in technical terms, high waist circumference, hypertension, dysglycemia, dyslipidemia. There is a huge body of evidence to suggest that the metabolic syndrome sets the stage for the development of full-blown type 2diabetes and premature cardiovascular disease. ${ }^{9-14}$ Other manifestations of obesity and the metabolic syndrome include joint disease, malignancies and sub fertility. Psychological implications resulting from social discrimination and low self esteem related to body dissatisfaction are manifesting increasingly in this population of individuals..$^{15,16}$

The rising prevalence of the metabolic syndrome, and the complications that have stemmed from the condition, ${ }^{17-19}$ has imposed a huge social and economic burden on the health care system, ${ }^{20-21}$ which is particularly relevant in the context of communities with very limited resources, such as Pakistan. Type 2 diabetes and the metabolic syndrome bear a strong genetic component. ${ }^{23-27}$ There is also abundant data to suggest that bad genetics are not the only culprits leading to this complex array of metabolic abnormalities. ${ }^{28}$ There are many environmental influences, relating to the consumption of unhealthy calorie dense diets and physical inactivity that have accompanied the process of expanding technology, urbanization and Westernization. 
Such influences have been shown to be independently associated with the development of the overweight state and the metabolic syndromethe precursors of type 2 diabetes. $^{28,29}$

Knowledge of this interplay between genetic. ${ }^{30}$ and environmental influences..$^{31,32}$ in the pathogenesis of the metabolic syndrome can lead to the development of screening protocols geared to the detection of an individual at high risk for the development of the condition. Such screening may help to identify and capture the victim of a potentially lethal cluster of metabolic abnormalities, at a potentially reversible or modifiable stage, or at a stage preceding the onset of full blown type 2 diabetes or cardiovascular disease.

We aimed to arrange for screening of potentially high risk individuals for presence of the metabolic syndrome when the patient already known to have diabetes presented for a checkup at the diabetes clinic. The screening, therefore, was targeted at two sets or strata of individuals: firstly, for the sibling of the type 2 diabetic presenting to the clinic, who, owing to their genetic predisposition, are at high risk for the presence of the metabolic syndrome. The second set included the spouse of the diabetic. The rationale behind the screening of the spouse is that the spouse is very likely to be sharing the same unhealthy lifestyles that the diabetic partner is or has been exposed to. This hypothetically places the spouse at a risk for the presence of the metabolic syndrome, irrespective of consanguity. There have been studies looking at the metabolic syndrome in the first degree relatives of type 2 diabetics conducted in Argentina. ${ }^{33}$ and Iran. ${ }^{34}$ However, to our knowledge, no major study in our region of Pakistan has looked at this specifically. The study done in Pakistan, most relevant to our study was conducted in $2005 .{ }^{35}$ This study addressed the metabolic risk factors, insulin resistance and lifestyle in children of type 2diabetes patients in Karachi, Pakistan. ${ }^{35}$ In this study, data were collected from 37 children/adolescents of type 2diabetes patients and 37 controls from children without diabetes, presenting to the Diabetes and Endocrinology clinic at the Aga Khan University Hospital. The authors concluded that the children of type 2diabetes patients had higher body mass index (BMI) and blood pressure than controls and that the hypothesis raised in the study needed confirmation through larger ones. ${ }^{35}$ Our study took one step further through involving the spouse of the diabetic. No regional study, in general, concerned with the metabolic syndrome, has incorporated the spouse of the type 2diabetic, who may not have any form of genetic link with the diabetic patient, whatsoever, but who may very well be sharing a great deal of lifestyle behavior and may very well be subjected to the same environmental influences as the latter. Including both the sibling and spouse of the type 2 diabetic may help to indicate whether it is the genetic predisposition or the environmental influences that predominate in the development of the metabolic syndrome.

It was hypothesized that conducting this survey would not only give us the opportunity to estimate the prevalence of the metabolic syndrome in the relatives of patients with type 2diabetes but would also serve as a screening tool to detect patients at high risk for the development of full blown type 2diabetes and its accompanying complications, the most dreaded of all being premature cardiovascular disease. This may help to create a better awareness, amongst health care professionals, of the magnitude of the problem. It may facilitate in the initiation of the counseling and management, including measures relating to lifestyle modification, and perhaps even pharmacotherapy, of these individuals, who may have previously gone unnoticed for long, despite sharing the same genetic and environmental milieu as the diabetic relative, and that too, at a potentially salvageable stage. This may help to establish more widespread screening health camps directed particularly to this high risk population.

\section{Aims and objectives}

a. To estimate the prevalence of the metabolic syndrome in blood and non-blood relatives of patients known to have type 2diabetes, presenting to the Diabetes clinic, as defined by the International Diabetes Federation (IDF) criteria for the definition of the metabolic syndrome.

\section{Methods}

\section{Study setting}

A tertiary care center in Karachi, Pakistan, namely, the Aga Khan University Hospital. AKUH.

\section{Study subjects}

These were incorporated into four groups:

Group 1: [Index Sibling (ISi)] - Sibling of patients presenting to the Diabetes clinic with known type 2 diabetes

Group 2: [Index Spouse (ISp)] Spouse of the same patient (as group 1) with known type 2 diabetes.

Group 3: [Referent Sibling (RSi)] - Sibling of non diabetic patients presenting to the clinic

Group 4: [Referent Spouse (RSp)] - Spouse of same non diabetic patient (as group 3)

Study design: Cross-sectional study.

\section{Sample size: 400 participants, with 200 index subjects and 200 referent subjects}

Using software EPI Info and assuming 34.8\% prevalence of metabolic syndrome in relatives of patients with type 2diabetes, ${ }^{33}$ with $95 \%$ confidence level, and a bound of error of $\pm 8 \%$, the estimated sample size was 367 . For sample size calculation for the factors associated with the metabolic syndrome in relatives of type 2 diabetics, the prevalence of risk factors was taken as $50 \%$, using a two sided alpha of 0.05 , with range of factors among non-exposed group of $46-100 \%$, odds ratio of 2 , with $80 \%$ power. Adding to $10 \%$ for non-response, that is, 33 samples to the calculated sample size, the final sample size was found out to be 400 study participants (index subjects $=200$; referent subjects $=200$ ).

\section{Sampling technique/methodology: case controlled study}

Inclusion criteria for index type 2diabetic: Both male \& female type 2 diabetic between ages of $18-70 \mathrm{yrs}$, with live spouse and at least one live sibling. 
Exclusion criteria for index type 2diabetic: Type 2diabetic whose siblings or spouse resided out of the city, and, therefore, may not have been accessible for the laboratory tests or physical measurements. Index type 2diabetic refusing consent to have their sibling and/or spouse enrolled in the study.

\section{Inclusion criteria for index sibling (ISi) and spouse (ISp)}

Sibling (brother or sister) of the presenting type 2diabetic.

Spouse of the same above-mentioned patient with known type 2diabetes. Both males \& females:

i. Age for sibling of type 2diabetic: 18 to 70 years

ii. Age for spouse of type 2diabetic: 18 to 70 years

\section{Exclusion criteria for index sibling (ISi) and spouse} (ISp)

i. Subjects already known to have type 2diabetes or subjects on anti diabetic drugs (Except if on metformin alone

ii. Subjects on anti hyperlipidemic agents

iii. Pregnant ladies

iv. Subjects known to have liver, renal, thyroid disease

v. Subjects known to have secondary cause of obesity (hypothyroidism, Cushings syndrome)

vi. Spouses who happened to be first cousins of type 2diabetics

vii. Spouses with a parent or sibling known to have type 2diabetes

viii. Sibling or spouse refusing consent for enrolment in study

\section{Inclusion criteria for referent sibling (RSi) and spouse (RSp)}

i. Sibling (brother or sister) of non diabetic patients, non diabetic physicians, non diabetic nursing staff, non diabetic receptionist $\&$ other non diabetic staff members at the clinic.

ii. Spouse of the same above-mentioned non diabetic subjects

iii. Both males \& females

iv. Age for sibling of non diabetic: 18 to 70 years

v. Age for spouse of non diabetic: 18 to 70 years

\section{Exclusion criteria for referent sibling (RSi) and spouse} (RSp)

i. Subjects already known to have type 2diabetes or subjects on anti diabetic drugs (except if on metformin alone).

ii. Subjects on anti hyperlipidemic agents

iii. Pregnant ladies

iv. Subjects known to have liver, renal, thyroid disease

v. Subjects known to have secondary cause of obesity (hypothyroidism, Cushings syndrome) vi. Spouse with a parent or sibling known to have type 2diabetes

vii. Sibling or spouse refusing consent for enrolment in study

\section{Data collection}

The sibling (brother or sister) of the index type 2diabetic [ISi] was subjected to an interview based questionnaire, which was designed to gather data on the sibling's sociodemographic variables (age, gender, ethnicity, occupation, education and socioeconomic class), the number of other first degree type 2diabetics in the family, from both the maternal and paternal side, and any possible medication used by the sibling, such as, for weight loss or high blood pressure. The physical measurements (weight, height, waist circumference, blood pressure and presence of acanthosis) as well as the laboratory investigations (FBS, Triglycerides and HDL) were recorded in this questionnaire. The spouse [ISp] was subjected to a similar interviewbased questionnaire.

\section{Taking of anthropometric measurements}

Weight: Weight was measured in $\mathrm{kg}$ and entailed the use of a weighing machine. This was placed on a flat surface on the ground. The needle was brought back to zero before the weight of each participant was taken. The participants were requested to remove their shoes before being weighed and remained in their uniforms, with all pockets emptied out and all jumpers/sweaters removed. They were made to stand with their feet together.

Height: It was measured with the help of a wall mounted stadiometer (calibrated in $\mathrm{cm}$ ). This too was positioned on a flat ground. The participant was asked to stand straight with his/her posture adjusted by the concerned data collector so that the back was straight and the highest point of both ears was at one level, that is to say, the head was not tilted to any one side, and with feet together.

Waist circumference: It was measured with the help of a measuring tape (calibrated in both $\mathrm{cm}$ and inches) positioned midway between lower rib margin and the iliac crest.

\section{Blood pressure}

Two Blood Pressure readings were obtained to measure both systolic and diastolic blood pressures. The measurements were taken at least 2 minutes apart, from the right arm, using an appropriate size cuff sphygmomanometer, with the subject in the sitting position. An apparatus validated by the American Heart Association was used.

The weight, height and waist circumference and blood pressure each were measured twice by the same research officer and the mean of the two values were used. In case of a major difference between the two readings, defined as a difference of more than 0.5 units, two further measurements were obtained and a mean of those were used.

\section{Selection of ISi and ISp}

The first group comprised 184 siblings (one sibling per index diabetic patient) of randomly selected type 2 diabetics, (conforming to inclusion criteria cited above), presenting to the diabetes clinic at the AKUH. As the second group, 184 spouses of the same diabetic were selected. Following informed consent, these individuals had their anthropometry and physical measurements, [blood pressure, weight, 
height, waist circumference, presence of acanthosis nigricans at the nape of the neck], measured by a dedicated well-trained research officer, as detailed above. This research officer arranged for them to reappear in the fasting state (preferably the next day, or earliest possible day), following a 12 hour period of fasting, for measurement of fasting blood sugar (FBS), Triglycerides (TG) and High Density Cholesterol (HDL): These laboratory tests were done at the main Aga Khan University laboratory, or at a hospital affiliated collection point nearest to the participant's residence, through a coupon system, which worked as follows: the AKUH clinical laboratory in-charge placed a billing code on the coupon against the budget code of the study. A scanned copy of this, with the signature of the principal investigator was electronically mailed to all the collection points spread across the city of Karachi. The principal investigator had copies of the same coupon to give to the study subject. The laboratory receptionist at each collection point was able to compare that against the scanned copy that they had been sent. In this way, the charges were deducted against the project budget account.

In case the eligible spouse and sibling had not accompanied the type 2diabetic at the clinic, at the time of selection for the study, they were requested to appear at the next earliest possible day for the anthropometrics to be taken at the clinic, by the dedicated research officer, following informed consent for this.

\section{Selection of RSi and RSp}

The third group included 182siblings of non diabetic patients visiting the clinic, as well as siblings of non diabetic physicians, nursing staff, receptionist and other staff members at the clinic. The fourth group included the 182spouses of the same non diabetic individuals from whom the sibling had been selected. These referent groups were subjected to the same eligibility and inclusion criteria as the index groups. The referent groups were subjected to the same questionnaire based interview, physical measurements and laboratory testing through the same strategy used for the index groups, as has been outlined above.

\begin{tabular}{llll}
\hline Group I ISi & Group2 ISp & Group 3 RSi & Group 4 RSp \\
\hline .Sibling Dm2 & .Spouse of & .Sibling of non & .Spouse of non \\
& Dm2 & Dm2 & Dm2 \\
Total I84 & Total I84 & Total I82 & Total I82 \\
\hline
\end{tabular}

\section{Data management analysis}

\section{Dependant variable}

Metabolic Syndrome as defined by the International Federation Diabetes. ${ }^{\text {IDF }}$ :

i. Central obesity, as defined by waist circumference $\geq 90 \mathrm{~cm}$ in males; $\geq 80 \mathrm{~cm}$ in females, if of Asian descent, and waist circumference $\geq 102 \mathrm{~cm}$ in males; $\geq 88 \mathrm{~cm}$ in females if Caucasian, plus any two of the factors defined:

ii. Raised triglyceride level $(>150 \mathrm{mg} / \mathrm{dl})$

iii. Reduced HDL-C level $(<40 \mathrm{mg} / \mathrm{dl}$ in males and $<50 \mathrm{mg} / \mathrm{dl}$ in females)

iv. Raised blood pressure $(>130 / 85 \mathrm{~mm} \mathrm{Hg})$

v. Raised fasting glucose $(>100 \mathrm{mg} / \mathrm{dl})$

\section{Independent variable}

Relation of the participant to the diabetic was a binary variable, constituting either sibling (brother or sister) of the type 2 diabetic, or spouse of the same type 2diabetic.

Sociodemographic variables:

i. Age of sibling and spouse of the type 2diabetic was recorded as a continuous variable.

ii. Gender of sibling and spouse of the type 2diabetic was categorized into male and female categories

iii. Ethnicity of sibling and spouse of the type 2diabetic, defined as the mother tongue according to the region of origin, was inquired of according to five main groups, namely: Urdu speaking, Punjabi speaking, Pushto speaking, Baloch speaking, Sindi speaking

iv. Socioeconomic status of sibling and spouse of the type 2diabetic was categorized into low middle class, with average income $\leq$ Rs $2,500 /$ month, and upper class, with average income $\geq 0,000$ / month.

v. Education of sibling and spouse of the type 2diabetic would be categorized into five groups:
a. No education;
b. Upto primary school;
c. Upto secondary school;
d. Graduation;
e. Postgraduation.

\section{Statistical analysis}

Statistical analysis of the data was done using SPSS version 16. All data entered through Epi Info was transported to SPSS 16 for purpose of analysis. Differences in proportion for index sibling and spouse, and referent sibling and spouse were assessed by using the pearson chi square test, whereas differences in means through the independent sample $\mathrm{T}$ test. Two sided $\mathrm{p}$ values $<0.05$ were considered statistically significant. The odds ratios for the development of the components of the metabolic syndrome for siblings of type 2 diabetics, compared to siblings of non diabetics, and the odds ratio for the development of the components of metabolic syndrome for spouses of type 2diabetics, versus spouses of non diabetics, were expressed with $95 \%$ confidence intervals.

\section{Results}

Of the selected subjects, complete data pertaining to sociodemographic variables, and MS components were available for 197 index siblings and spouses, while for 187referent siblings and spouses.

The descriptive characteristics of the study population (Tables $1 \& 2)$ were as follows:

On univariate analysis, the metabolic syndrome risk factors (component factors) for siblings are shown in Tables 3A, 3B, 4A\&4B Paste hear 
Table I Descriptive characteristics of sibling group of study population (sibling of index diabetic-ISi; sibling of RSi)

\begin{tabular}{|c|c|c|c|c|}
\hline & Total, $\mathrm{n}=197$ & Index sibling, $n=1 / 2$ & Referent sibling, $n=85$ & $P$ value \\
\hline Age, in years & $34.7 \pm 10.6$ & $34 \pm 10.7$ & $35.7 \pm 10.5$ & 0.24 \\
\hline \multicolumn{5}{|l|}{ Gender } \\
\hline Male & $122(61.9)$ & $67(59.8)$ & $55(64.7)$ & 0.55 \\
\hline Female & $75(38.1)$ & $45(40.2)$ & $30(35.3)$ & \\
\hline \multicolumn{5}{|l|}{ Ethnicity } \\
\hline Urdu speaking & $105(53.3)$ & $66(58.9)$ & $39(45.9)$ & 0.08 \\
\hline All others & $46(54.1)$ & $46(4 I . I)$ & $46(54.1)$ & \\
\hline \multicolumn{5}{|l|}{ Education } \\
\hline Illiterate & $\mathrm{I}(0.5)$ & 0 & $\mathrm{I}(\mathrm{I} .2)$ & 0.01 \\
\hline Schooling & $77(4 I .2)$ & $33(32.4)$ & $44(51.8)$ & \\
\hline Graduate and above & $109(58.3)$ & $69(67.6)$ & $40(47.1)$ & \\
\hline
\end{tabular}

Table 2 Descriptive characteristics of spousal group of study population (spouse of index diabetic-ISp; spouse of non-diabetic-RSp)

\begin{tabular}{lllll}
\hline & Total, $\mathbf{n = I 8 7}$ & Index spouse, $\mathbf{n = 8 4}$ & Referent spouse, $\mathbf{n = 1 0 3}$ & P value \\
\hline $\begin{array}{l}\text { Age, in years } \\
\text { Gender }\end{array}$ & $46.3 \pm 10.4$ & $49.6 \pm I I .0$ & $48.7 \pm 9.3$ & 0.1 \\
Male & & & & \\
Female & $96(5 I .3)$ & $48(57.1)$ & $48(46.6)$ & 0.18 \\
Ethnicity & $91(48.7)$ & $36(42.9)$ & $55(53.4)$ & \\
Urdu speaking & & & & 0.46 \\
All others & I05(56.I) & $50(59.5)$ & $55(53.4)$ & \\
Education & $82(43.9)$ & $34(40.5)$ & $48(46.6)$ & \\
Illiterate & & & & 0.15 \\
Schooling & $8(4.7)$ & $I(1.5)$ & $7(6.8)$ & \\
Graduate and above & $85(50)$ & $38(56.7)$ & $49(47.6)$ & \\
\hline
\end{tabular}

Table 3A On univariate analysis, the metabolic syndrome risk factors (component factors) for siblings

\begin{tabular}{|c|c|c|c|c|}
\hline & Total, $\mathrm{n}=\mid 97$ & Index sibling, $n=\mid$ | 2 & Referent sibling, $n=85$ & $P$ value \\
\hline \multicolumn{5}{|l|}{ Metabolic Syndrome } \\
\hline Normal & $162(82.2)$ & 94(83.9) & $68(80)$ & 0.57 \\
\hline MeT & $35(17.8)$ & $18(16.1)$ & $17(20)$ & \\
\hline Waist circumference & $93.3 \pm 11.1$ & $134.3 \pm 33.3$ & $91.1 \pm 10.5$ & 0.01 \\
\hline Triglyceride & $120.5 \pm 1 \mid 8.8$ & $94.9 \pm 11.3$ & $91.1 \pm 10.5$ & 0.76 \\
\hline Median[IQR] & $92[80-13]$ & $91[80-106]$ & $100.5[66-166.7]$ & \\
\hline HDL & $47.5 \pm 9.05$ & $48.8 \pm 8.3$ & $46.3 \pm 9.8$ & 0.53 \\
\hline Median[IQR] & $52[42-73]$ & $67[44.5-106]$ & $46[4 \mid-53]$ & \\
\hline Fasting blood glucose & $91.6 \pm 19.2$ & $92 \pm 23.8$ & $91 \pm 10.1$ & 0.69 \\
\hline Systolic blood pressure & $|18.1 \pm| 4.8$ & $117.7 \pm 12.6$ & $118.5 \pm 17.3$ & 0.7 \\
\hline Diastolic blood pressure & $79.8 \pm 8.9$ & $80.0 \pm 7.7$ & $79.5 \pm 10.3$ & 0.73 \\
\hline BMI & $27.35 \pm 7.2$ & $30.1 \pm 6.9$ & $26.6 \pm 4.8$ & 0.08 \\
\hline
\end{tabular}


Table 3B Represents the final model for siblings (Multiple Logistic Regression)

\begin{tabular}{lll}
\hline & Odd ratio[95\% Cl] & $\mathbf{P}$ value \\
\hline Waist Circumference & $1.04[1.006-1.07]$ & 0.02 \\
\hline
\end{tabular}

Table 4A univariate analysis of metabolic syndrome risk factors (component factors) for spouses

\begin{tabular}{|c|c|c|c|c|}
\hline & Total, $\mathbf{n}=\mid \mathbf{8 7}$ & Index spouse, $n=84$ & Referent spouse, $n=103$ & P value \\
\hline \multicolumn{5}{|c|}{ Metabolic Syndrome } \\
\hline Normal & $106(56.7)$ & $48(57.1)$ & $58(56.3)$ & 0.99 \\
\hline MeT & $8 I(43.3)$ & $36(42.9)$ & $45(43.7)$ & \\
\hline $\begin{array}{l}\text { Waist } \\
\text { circumference }\end{array}$ & $97.3 \pm 13.7$ & $101.1 \pm 12.2$ & $94.2 \pm 14.2$ & 0.001 \\
\hline Triglyceride & $143.3 \pm 83.9$ & $140.2 \pm 70.9$ & $145.6 \pm 92.6$ & 0.69 \\
\hline $\mathrm{HDL}$ & $47.5 \pm 10.9$ & $47.3 \pm 11.2$ & $47.7 \pm 10.8$ & 0.82 \\
\hline $\begin{array}{l}\text { Fasting blood } \\
\text { glucose }\end{array}$ & $92.7 \pm 14.2$ & $92.3 \pm 14.2$ & $93.1 \pm 14.2$ & 0.71 \\
\hline $\begin{array}{l}\text { Systolic blood } \\
\text { pressure }\end{array}$ & $120.8 \pm|6|$. & $123.6 \pm 17.4$ & I | $8.4 \pm \mid 4.6$ & 0.02 \\
\hline $\begin{array}{l}\text { Diastolic } \\
\text { blood } \\
\text { pressure }\end{array}$ & $81.0 \pm 9.7$ & $83.1 \pm 9.8$ & $79.3 \pm 9.4$ & 0.008 \\
\hline BMI & $29.7 \pm 15.9$ & $32.7 \pm 22.9$ & $27.2 \pm 4.7$ & 0.03 \\
\hline
\end{tabular}

Table 4B Final model for spouses

\begin{tabular}{lll}
\hline & Odd ratio[95\% Cl] & P value \\
\hline Waist circumference & I.03[I.007-I.06] & 0.01 \\
BMI & $1.07[0.99-1.14]$ & 0.056 \\
\hline
\end{tabular}

\section{Discussion}

The strength of our study is that it has compared the constituents of the metabolic syndrome in both sibling and spouse of the individual with known DM2. Our study found no significant association in the overall prevalence of the metabolic syndrome in siblings and spouses of individuals with diabetes, versus siblings and spouses of non-diabetics. However, where individual components of metabolic syndrome are concerned (waist circumference, blood pressure, blood sugar and blood lipid levels), there was a significant association of high waist circumference in both siblings and spouses of individuals with diabetes as compared to siblings and spouses of individuals without diabetes (Table 3B\&4B).

Yusuf et al. ${ }^{36}$ sought to determine whether markers of obesity, such as waist circumference, waist-hip ratio would be stronger indicators of myocardial infarction versus the conventional measure of body mass index. They found that waist circumference was strongly related to myocardial infarction risk. The International Day for Evaluation for abdominal obesity [IDEA] study emphasized waist circumference to be an important clinical marker for incidence of coronary heart disease and diabetes mellitus across the globe..$^{37}$ This applied even in case of individuals with normal weight. Kamran et al..$^{38}$ conducted a survey in Okara, Pakistan to compare coronary artery disease risk factors in abdominal obesity, versus general obesity with normal waist circumference, in adult males. The investigators concluded that both higher body mass index and higher waist circumference were associated with increased risk of coronary heart disease, with a significantly higher risk in the high waist circumference group.

Khan et al compared glucose tolerance of spouses of patients with type 2diabetes attending a diabetes clinic with spouses of non diabetic subjects. The investigators concluded that the former group had a significantly greater risk of type 2diabetes than the latter. The participants of the investigation underwent BMI assessment, as well as adjustment for this parameter on multiple logistic regression, with risk of diabetes remaining significant [2.11 (95\% CI 1.74-5.1)]. Central obesity was not measured in their study. ${ }^{39}$ Di Castelnuovo and his team through a meta-analysis on spousal concordance for cardiovascular risk factors state that very few studies have investigated spousal concordance for such risk factors as the metabolic syndrome, and more data was required for meaningful analysis. ${ }^{40}$ Leong et al conducted a systematic review and meta-analysis to examine spousal association for diabetes. The group concluded that spousal history of diabetes was associated with $26 \%$ increase risk of diabetes. ${ }^{41}$

A Nation-wide survey conducted in Korea concluded that there was a significant spousal concordance of the metabolic syndrome in the Korean population relating to sharing of environmental factors leading to the development of the metabolic syndrome. Their group found strong spousal correlations for each component of the metabolic syndrome. ${ }^{42}$ among the 5components of metabolic syndrome, prevalence of abdominal obesity had the greatest impact on the difference between Korean and Western populations. Our study also showed a significant association between central obesity, as evidenced by high waist circumference, in spouses of diabetics as compared to those of non-diabetics (OR 1.03, 95\% CI 1.007-1.06). 
The reason for the lack of association of other MS component factors (other than abdominal obesity) in our study could be related to the smaller sample size of a hospital-based cohort and/or to the fact that high waist circumference may be an earlier indicator for the later development of the full-blown MS in these individuals.

Our study revealed siblings of subjects with type 2diabetes to have significantly higher waist circumference as compared with siblings without diabetes (1.04, 95\% CI 1.006-1.07). Sibling history of type 2diabetes has been known to elevate diabetes risk by three fold. ${ }^{43}$ Knuiman et al. ${ }^{44}$ looked at familial correlations and heritability for cardiovascular risk factors. They found that in nuclear families of Western Australia there existed a high correlation of BMI, cholesterol, systolic and diastolic blood pressure. The degree of correlation was greater for siblings than for spouses. They did not, however, measure waist circumference in this Caucasian population sample. In a large Chinese rural population, siblings aged 24-64years were recruited from 5,224families. Their data demonstrated significant correlation in body fat, lipid profile, fasting glucose levels and blood pressure amongst siblings. The correlation was particularly significant for siblings with smaller age differences, ${ }^{45}$ suggesting both genetic and environmental influences. Spousal association was not determined in their study.

Our study was limited by the fact that it involved individuals appearing at a hospital-based clinic, as compared with a communitybased one. We did not review dietary habits and physical activity levels of spouses and siblings, to determine similarities with the index diabetic. Previous work has revealed spousal and sibling similarities as regards social activities and dietary practices. ${ }^{42-47}$ There may be an even stronger correlation of such dietary practices in the South Asian community, where the father/ husband is more likely to be the family leader and determinant of which food items are consumed, as well as practices, in general, adopted by the entire family. Our work may serve as a foot-step to conducting a broader community-based investigation, targeting clusters of families spread over the nation, for the evaluation of their metabolic parameters. Our findings re-iterate that abdominal obesity, through monitoring of waist circumference- a cost effective measure in a resource poor community- as opposed to BMI alone, be an integral part of assessment for cardiovascular risk factors. While inquiring about a family history of type 2diabetes or cardiovascular disease, we urge and reinforce health care providers to question spousal history of cardio-metabolic disease, in addition to the traditional enquiry into history of disease in first degree relatives alone. Counseling regarding lifestyle modification may best be provided to the couple, as opposed to a single element of a family, even if one partner appears to be non-diseased at the present time. This may help to shape a healthier future for the entire family unit in the long run.

\section{Acknowledgments}

None.

\section{Conflicts of interest}

Authors declare that there is no conflict of interest.

\section{Funding}

None.

\section{References}

1. Golden SH, Robinson KA, Saldanha I, et al. Clinical reviews: Prevalence and incidence of endocrine and metabolic disorders in the United States: a comprehensive review. J Clin Endocrinol Metab. 2009;94(6):1853-1878.

2. King H, Aubert RE, Herman WH. Global burden of diabetes, 1995-2025: prevalence, numerical estimates, and projections. Diabetes Care. 1998;21(9):1414-1431.

3. Chan JC, Malik V, Jia W, et al. Diabetes in Asia: epidemiology, risk factors, and pathophysiology. JAMA. 2009;301(20):2129-2140.

4. Alwan A, King H. Diabetes in the Eastern Mediterranean (Middle East) region: the World Health Organization responds to a major public health challenge. Diabet Med. 1995;12(12):1057-1058.

5. Adusumilli PS, Stiles BM. Obesity epidemic in the West: warning signs in the East. Natl Med J India. 2003;16(2):110-111.

6. Wild S, Roglic G, Green A, et al. Global prevalence of diabetes: estimates for the year 2000 and projections for 2030. Diabetes Care. 2004;27(5):1047-1053.

7. Rathmann W, Giani G. Global prevalence of diabetes: estimates for the year 2000 and projections for 2030. Diabetes Care. 2004;27(10):2568-2569.

8. Lefebvre P, Pierson A. The global challenge of diabetes. World Hosp Health Serv. 2004;40(3):37-40.

9. Chen LJ, Fox KR, Haase A, et al. Obesity, fitness and health in Taiwanese children and adolescents. Eur J Clin Nutr. 2006;60(12):1367-1375.

10. Dietz WH. The obesity epidemic in young children. Reduce television viewing and promote playing. BMJ (Clinical research ed). 2001;322(7282):313-314.

11. Schneider MB, Brill SR. Obesity in children and adolescents. Pediatrics in review. American Academy of Pediatrics. 2005;26(5):155-162.

12. Pietrobelli A, Espinoza MC, De Cristofaro P. Childhood Obesity: Looking Into the Future. Angiology. 2008;59(2 Suppl):30S-33S.

13. Reilly JJ. Obesity in childhood and adolescence: evidence based clinical and public health perspectives. Postgraduate medical journal. 2006;82(969):429-437.

14. Bruno G, Merletti F, Biggeri A, et al. Metabolic syndrome as a predictor of all-cause and cardiovascular mortality in type 2 diabetes: the Casale Monferrato Study. Diabetes Care. 2004;27(11):2689-2694.

15. Schwimmer JB, Burwinkle TM, Varni JW. Health-related quality of life of severely obese children and adolescents. JAMA. 2003;289(14):1813-1819.

16. Shin NY, Shin MS. Body dissatisfaction, self esteem, and depression in obese Korean children. The Journal of Paediatrics. 2008;152(4):502-506.

17. Rossi B, Sukalich S, Droz J, et al. Prevalence of metabolic syndrome and related characteristics in obese adolescents with and without polycystic ovary syndrome. J Clin Endocrinol Metab. 2008;93(12):4780-4786.

18. Cordero Fort A, Moreno Arribas J, Martin Arnau A, et al. Prevalence of metabolic syndrome and association with ischemic heart disease in cardiological outpatients. Rev Clin Esp. 2006;206(6):259-265.

19. Ramaraj R, Chellappa P. Cardiovascular risk in South Asians. Postgrad Med J. 2008;84(996):518-523.

20. Katzmarzyk PT, Janssen I. The economic costs associated with physical inactivity and obesity in Canada: an update. Can J Appl Physiol. 2004;29(1):90-115.

21. Khuwaja AK. Epidemic of obesity: prevention must start in childhood. $J$ Ayub Med Coll Abbottabad. 2004;16(4):93. 
22. Khowaja LA, Khuwaja AK, Cosgrove P. Cost of diabetes care in outpatient clinics of Karachi, Pakistan. BMC Health Serv Res. 2007;7:189.

23. Li H, Isomaa B, Taskinen MR, et al. Consequences of a family history of type 1 and type 2 diabetes on the phenotype of patients with type 2diabetes. Diabetes Care. 2000;23(5):589-594.

24. Groop L, Forsblom C, Lehtovirta M, et al. Metabolic consequences of family history of NIDDM (the Botnia study): evidence for sex-specific parental effects. Diabetes. 1996;45(11):1585-1593.

25. Vauhkonen I, Niskanen L, Vanninen E, et al. Defects in insulin secretion and insulin action in non-insulin-dependent diabetes mellitus are inherited. Metabolic studies on offspring of diabetic probands. $J$ Clin Invest. 1998;101(1):86-96.

26. Reaven GM. Insulin resistance, the insulin resistance syndrome, and cardiovascular disease. Panminerva Med. 2005;47(4):201-210.

27. Hansen BC. The metabolic syndrome X. Ann N Y Acad Sci. 1999;892:1-24

28. Ford ES, Mokdad AH. Epidemiology of obesity in the Western Hemisphere. J Clin Endocrinol Metab. 2008;93(11 Suppl 1):S1-S8.

29. Margetts B. WHO global strategy on diet, physical activity and health Editorial. Public Health Nutr. 2004;7(3):361-363.

30. Recabarren SE, Smith R, Rios R, et al. Metabolic profile in sons of women with polycystic ovary syndrome. J Clin Endocrinol Metab. 2008;93(5):1820-1826.

31. Misra A, Khurana L. Obesity and the metabolic syndrome in developing countries. J Clin Endocrinol Metab. 2008;93(11 Suppl 1):S9-S30.

32. Pan WH, Yeh WT, Weng LC. Epidemiology of metabolic syndrome in Asia. Asia Pac J Clin Nutr. 2008;17(Suppl 1):37-42.

33. Siewert S, Filipuzzi S, Codazzi L, et al. Impact of metabolic syndrome risk factors in first-degree relatives of type 2 diabetic patients. Rev Diabet Stud. 2007;4(3):177-184.

34. Amini M, Janghorbani M. Diabetes and impaired glucose regulation in first-degree relatives of patients with type 2 diabetes in isfahan, iran: prevalence and risk factors. Rev Diabet Stud. 2007;4(3):169-176.

35. Rashid AS, Jabbar A, Michels RPJ, et al. Metabolic Risk Factors, insulinresistance and lifestyle in children of type 2 diabetes patients in Karachi, Pakistan. Diabetes Res Clin Pract. 2008;80(3):399-404.
36. Yusuf S, Hawken S, Ounpuu S, et al. Obesity and the risk of myocardial infarction in 27000 participants from 52 countries: a case-control study. Lancet. 2005;366(9497):1640-1649.

37. Balkau B, Deanfield JE, Despres JP, et al. International Day for the Evaluation of Abdominal Obesity (IDEA): a study of waist circumference, cardiovascular disease, and diabetes mellitus in 168,000 primary care patients in 63 countries. Circulation. 2007;116(17):1942-1951.

38. Kamran SM, Iftikhar R, Khan A, et al. Comparison of CAD risk factors in abdominal obesity versus general obesity with normal waist circumference in adult males. JPMA. 2014;64(4):394-398.

39. Khan A, Lasker SS, Chowdhury TA. Are Spouses of Patients with Type 2 Diabetes at Increased Risk of Developing Diabetes? Diabetes Care. 2003;26(3):710-712.

40. Di Castelnuovo A, Quacquaruccio G, Donati MB, et al. Spousal concordance for major coronary risk factors: a systematic review and metaanalysis. Am J Epidemiol. 2009;169(1):1-8.

41. Leong A, Rahme Elham, Dasgupta Kaberi. Spousal diabetes as a diabetes risk factor: a systematic review and meta-analysis. BMC Med. 2014; $12: 1-12$.

42. Kim HC, Kang DR, Choi KS, et al. Spousal concordance of metabolic syndrome in 3141 Korean couples: A nationwide survey. Ann Epidemiol. 2006;16(4):292-298.

43. Hemminki, Li X, Sundquist K, et al. Familial risks for type 2diabetes in Sweden. Diabetes Care. 2010;33(2):293-297.

44. Knuiman MW, Divitini ML, Welborn TA, et al. Familial Corelations, cohabitation effects, and heritability for cardiovascular risk factors. Annals of Epidemiology. 1996;6(3):188-194.

45. Feng Y, Zang T, Xu X. Familial Aggregation of MS and its Components in a Large Chinese Population. Obesity. 2008;16(1):125-129.

46. Kolonel LN, Lee J. Husband-wife correspondence in smoking, drinking and dietary habits. Am J Clin Nutr. 1981;34(1):99-104.

47. Knowler WC, Fowler JH. The spread of obesity in a large social network over 32years. N Engl J Med. 2007;357(4):370-379. 